\title{
UM ACENO DO CENTRO-OESTE BRASILEIRO Sobre o impacto das revistas em programas de pós-graduação
}

Moisés Lopes

Universidade Federal do Mato Grosso

Departamento de Antropologia | Cuiabá, Brasil

sepolm@gmail.com | ORCID iD: 0000-0002-7506-707X

Marcos Aurélio da Silva

Universidade Federal do Mato Grosso

Instituto de Saúde Coletiva | Cuiabá, Brasil

marcoaureliosc@hotmail.com | ORCID iD: 0000-0002-4978-1990

A

imagem do conhecimento circulando sem fronteiras nacionais é bastante apelativa e já foi utilizada inclusive como programa de governo de promoção à consolidação, expansão e internacionalização da ciência, tecnologia e inovação nacionais. O programa que teve como foco o envio de estudantes brasileiros para o exterior teve curta existência e sucumbiu alguns anos depois de sua criação recheado de polêmicas, críticas e denúncias. A Coordenação de Aperfeiçoamento de Pessoal de Nível Superior (CAPES) teve um papel fundamental não apenas neste programa, mas tem também no "investimento e na formação de recursos de alto nível no país e no exterior", sendo inclusive uma das principais atividades da fundação, seguidas da "avaliação da pósgraduação strictu-sensu", do "acesso e divulgação da produção científica", da "promoção da cooperação científica internacional" e da "indução e fomento da formação inicial e continuada de professores para a educação básica nos formatos presencial e a distância". Assim, tendo como atividades principais a indução, o fomento, o investimento e a formação no país e no exterior, a CAPES tem desenvolvido programas, políticas e ações com o fim de estimular a ciência, tecnologia e 
inovação nacionais em todas as áreas do conhecimento. Nos últimos anos o que temos assistido, no entanto, é uma política específica que sob o "pretexto de internacionalização"l (Campos 2020) tem, em alguma medida, apesar de algumas iniciativas esparsas, reforçado as desigualdades existentes entre as áreas do conhecimento e regiões do país.

Este relato pretende abordar a experiência de criação e consolidação de um periódico científico nacional na área da antropologia, situado na Amazônia Legal brasileira. Vinculado a um Programa de Pós-Graduação em Antropologia Social da Universidade Federal de Mato Grosso (PPGAS-UFMT), também recém-criado, e que tem sido um elemento fundamental para dar visibilidade para pesquisas desenvolvidas fora do circuito dos grandes centro-metropolitanos do Brasil, bem como pesquisas do/no exterior, feito que tem alcançado sem apoio financeiro, de pessoal e de recursos provenientes de agências de fomento, como a CAPES ou o GNPq. Deste modo, partiremos do relato da construção da Aceno e em seguida discutiremos questões que envolvem a indexação e a avaliação de um periódico no contexto brasileiro.

\section{A Aceno - Revista de Antropologia do Centro-Oeste}

Lá pelos idos de 2013 é que começa a história da Aceno, quase que simultaneamente à criação do programa de pósgraduação ao qual está vinculada. Olhando assim, rapidamente, foram apenas sete anos. Mas a passagem do tempo foi e tem assumido como característica central a relatividade $^{2}$ na construção diuturna deste periódico científico localizado no centro geodésico da América do Sul. O nome, resultado de uma "brincadeira com as palavras" realizada por professores em uma reunião no departamento de antropologia, já mostrava um pouco as expectativas do projeto, suas aspirações e os desafios que ele assumiria na geopolítica do conhecimento. Assim, a palavra ACENO, como na referida brincadeira, era

\footnotetext{
${ }^{1}$ Luiz Augusto Campos, em texto neste fórum, ao usar essa expressão faz referência ao Sistema Qualis-CAPES como um "sistema mais amplo de fortalecimento da infraestrutura de Ciência e Tecnologia brasileira, focado mais em induzir avanços do que em avaliar campos nacionais de modo estanque" (2020:9).

2 Como definida em sua teoria da relatividade, a "diferença entre passado, presente e futuro é apenas uma persistente ilusão". Tal relação para Einstein é estabelecida mediante o vínculo entre tempo e velocidade de um corpo.
} 
simultaneamente um "abanar de mãos", um gesto, um sinal de identificação de um grupo de jovens professores - em sua maioria, naquele momento, recém-fixados - no Centro-Oeste do Brasil; bem como uma referência, através da sigla ACENO (Antropologia do CENtro-Oeste), a dois eventos então consolidados: a REA-ABANNE (Reunião Equatorial de Antropologia - Reunião de Antropólogos do Norte-Nordeste) e a Reunião de Antropologia do Mercosul.

Pela característica própria ao trabalho de investigação de antropólogas e antropólogos que, uma vez em campo, sempre "levam a sério" as falas de seus interlocutores, o nome "acabou pegando". Inicialmente, graças à ideia de fazer um evento com todos os nossos departamentos irmãos do Centro-Oeste que haviam ficado "formalmente de fora" enquanto instituições das reuniões do Norte-Nordeste-Mercosul-Equador (tal evento nunca foi realizado ou sequer cogitado "a sério", diga-se de passagem). Em seguida, pela transposição do nome do suposto evento para a revista.

Neste sentido, a Aceno já nasce com o objetivo de marcar sua posição fora do eixo das grandes capitais do país, se constituindo como um espaço não apenas para a divulgação do conhecimento local (dimensão importante da revista), mas com a aspiração de se tornar um fórum permanente de debates e diálogos da produção científica das humanidades, em especial da antropologia. Isso fica explícito em seu primeiro editorial: "[a revista] tem como propósito se constituir em um espaço permanente para o debate, a construção do conhecimento e a interlocução entre antropólogos e pesquisadores de áreas afins, do país e do exterior" (Lopes 2014:7).

Nessa busca por historicizar a criação e a publicação da Aceno, que, embora não tenha alcançado sua primeira década, vem mantendo de forma ininterrupta o trabalho de publicação e divulgação científica, é importante destacar ser este um empreendimento impetuoso, mesmo que marcado pela inocência, de um conjunto de professores e professoras de um programa de pós-graduação em antropologia social que acabara de ser aprovado pela CAPES em uma universidade pública "pequena", do "interior" do país. Uma trajetória de muito trabalho, várias dificuldades e entraves, mas também de abundantes aprendizados e realizações que terminaram por projetar o nome da revista, de seu projeto editorial e do PPGAS da UFMT, para além das fronteiras do território nacional. Seja por um significado ou outro assumido pela já referida 
"brincadeira" que deu nome ao periódico, a Aceno - Revista de Antropologia do Centro-Oeste ultrapassou, tal como pretendíamos inicialmente, sua vinculação local ou regional, como vemos na Tabela 3 abaixo.

Esse Programa de Pós-Graduação era um sonho antigo da UFMT, que só veio a se concretizar em 2013, a partir da chegada, entre 2004 e 2011 , de novos docentes no departamento de antropologia - o que ocasionou um processo de reformulação departamental. O PPGAS/UFMT está organizado em duas linhas de pesquisa que cobrem um leque amplo de objetos e de campos de estudos na antropologia. São elas: 1 - Etnicidades, Territorialidades e Cosmologia; 2 Sociabilidades, Identidades e Subjetividades.

Essa vinculação a um programa de pós-graduação que começou com apenas oito docentes (um docente a mais do que o número mínimo exigido pela CAPES em 2013), conjunto constituído majoritariamente por recém-doutores em início de carreira, faz da Aceno um case de sucesso. A começar pelo número de professores realmente engajados na produção de toda a revista - os dois autores do presente texto -, do recebimento de artigos recebidos à publicação final, sem contar com auxílio de diagramadores e revisores de texto. Isso é compreensível num programa hoje com apenas 13 professores, sendo que 10 são do quadro de efetivos da UFMT, a maioria do Departamento de Antropologia, sobrecarregados de encargos administrativos, o que torna a editoração de uma revista pouco atrativa - raramente conseguimos alguma recompensa na carga horária por esse trabalho. Além disso, as escassas bolsas do programa fazem com que contemos com poucos alunos para contribuir, apesar de termos montado por duas vezes comitês editoriais júnior, com o intuito de iniciá-los nas artes da editoração.

Nossos poucos recursos, no entanto, não nos impediram de variarmos e de sempre melhorarmos o projeto editorial da Aceno. Ao contrário de muitas revistas, os artigos livres não são os únicos protagonistas dos volumes publicados, que dão centralidade principalmente a dossiês temáticos. Além de espaço para resenhas, foi criada também uma seção de conferências, onde são publicados trabalhos apresentados por convidados externos nos eventos do PPGAS. Por fim, a seção de ensaios fotográficos tem atraído muitos pesquisadores que utilizam imagens em suas pesquisas ou como modo de etnografar. Uma das metas futuras é a regularidade de uma seção para traduções - até hoje um único artigo traduzido foi publicado. 


\begin{tabular}{cc}
\hline Seções & Total de Publicações \\
\hline Dossiês & 124 \\
Artigos Livres & 30 \\
Resenhas & 14 \\
Outros & 12 \\
\hline Total Geral & 180 \\
Números Publicados $^{3}$ & 13 \\
\hline
\end{tabular}

Tabela 1 - Total de Publicações (2014-2020)

\begin{tabular}{cccccccccccccc}
\hline Seções & V1 & V1 & V2 & V2 & V3 & V3 & V4 & V4 & V5 & V5 & V6 & V6 & V7 \\
& N1 & N2 & N3 & N4 & N5 & N6 & N7 & N8 & N9 & N10 & N11 & N12 & N13 \\
\hline Dossiês & 0 & 4 & 16 & 0 & 16 & 17 & 15 & 8 & 7 & 14 & 5 & 15 & 7 \\
Livres & 5 & 1 & 1 & 3 & 0 & 0 & 4 & 3 & 4 & 1 & 3 & 2 & 3 \\
Resenhas & 0 & 1 & 1 & 2 & 0 & 2 & 2 & 0 & 0 & 2 & 2 & 2 & 0 \\
Outros & 0 & 0 & 1 & 1 & 1 & 0 & 1 & 0 & 0 & 3 & 2 & 1 & 2 \\
\hline Total & 5 & 6 & 19 & 6 & 17 & 19 & 22 & 11 & 11 & 20 & 12 & 20 & 12 \\
\hline
\end{tabular}

Tabela 2 - Publicações por Seção

\section{Redes, Indexação e Avaliação de Periódicos}

Ainda que um periódico ligado a um programa de pósgraduação possa ter como objetivo fomentar a publicação de artigos por parte de seus pesquisadores, docentes e discentes, a Aceno sempre se colocou mais como vetor de publicações em nível nacional do que como divulgadora oficial dos trabalhos do PPGAS/UFMT. Um dos motivos é que, por conta de sermos um programa relativamente novo, publicar em revistas mais bem avaliadas pelo Qualis Periódicos foi uma meta conjunta dos integrantes do programa. No entanto, nunca deixamos de incentivar os docentes e, principalmente, os discentes, a publicarem na Aceno, sempre cuidando para não ultrapassarmos o percentual (de 20\%) de endogenia, frequentemente muito baixo. Isso fica claro quando analisamos, por exemplo, a filiação dos autores que publicaram na Aceno, conforme apresentada na tabela abaixo.

\footnotetext{
3 Até o ano de 2019 a revista era semestral; no ano de 2020 a revista alterou sua periodicidade e tornou-se quadrimestral.
} 


\begin{tabular}{|c|c|c|c|c|c|c|c|c|c|c|c|c|c|c|}
\hline $\begin{array}{l}\text { Procedênci } \\
\text { a do(a)s } \\
\text { autores(as) }\end{array}$ & $\begin{array}{l}\text { V1 } \\
\text { N1 }\end{array}$ & $\begin{array}{l}\text { V1 } \\
\text { N2 }\end{array}$ & $\begin{array}{l}\text { V2 } \\
\text { N3 }\end{array}$ & $\begin{array}{l}\text { V2 } \\
\text { N4 }\end{array}$ & $\begin{array}{l}\text { V3 } \\
\text { N5 }\end{array}$ & $\begin{array}{l}\text { V3 } \\
\text { N6 }\end{array}$ & $\begin{array}{l}\text { V4 } \\
\text { N7 }\end{array}$ & $\begin{array}{l}\text { V4 } \\
\text { N8 }\end{array}$ & $\begin{array}{l}\text { V5 } \\
\text { N9 }\end{array}$ & $\begin{array}{l}\text { V5 } \\
\text { N10 }\end{array}$ & $\begin{array}{l}\text { V6 } \\
\text { N11 }\end{array}$ & $\begin{array}{l}\text { V6 } \\
\text { N12 }\end{array}$ & $\begin{array}{l}\text { V7 } \\
\text { N13 }\end{array}$ & Total \\
\hline $\begin{array}{l}\text { PPGAS/ } \\
\text { UFMT }\end{array}$ & 0 & 2 & 3 & 2 & 2 & 4 & 2 & 2 & 1 & 0 & 2 & 2 & 2 & 24 \\
\hline $\begin{array}{l}\text { Centro- } \\
\text { Oeste }\end{array}$ & 1 & 0 & 6 & 1 & 6 & 7 & 5 & 2 & 4 & 4 & 10 & 12 & 5 & 63 \\
\hline Sudeste & 4 & 2 & 6 & 1 & 3 & 6 & 7 & 5 & 6 & 11 & 4 & 3 & 10 & 68 \\
\hline Sul & 1 & 0 & 3 & 2 & 1 & 5 & 2 & 0 & 0 & 4 & 1 & 6 & 1 & 26 \\
\hline Nordeste & 0 & 0 & 4 & 0 & 8 & 7 & 5 & 0 & 0 & 2 & 1 & 4 & 1 & 32 \\
\hline Norte & 2 & 1 & 1 & 2 & 9 & 2 & 6 & 5 & 3 & 2 & 1 & 4 & 3 & 41 \\
\hline $\begin{array}{l}\text { América do } \\
\text { Sul }\end{array}$ & 0 & 3 & 1 & 0 & 0 & 2 & 1 & 0 & 0 & 0 & 0 & 0 & 0 & 7 \\
\hline $\begin{array}{l}\text { Outros } \\
\text { países }\end{array}$ & 0 & 0 & 3 & 0 & 0 & 0 & 2 & 0 & 3 & 0 & 0 & 0 & 0 & 8 \\
\hline $\begin{array}{c}\text { Total de } \\
\text { autores(as) }\end{array}$ & 8 & 8 & 26 & 8 & 29 & 33 & 31 & 14 & 17 & 23 & 19 & 31 & 22 & 269 \\
\hline
\end{tabular}

Tabela 3 - Procedência regional/ nacional do Autor

Como vemos, em 13 números da Aceno, houve apenas 24 contribuições de professores ou discentes vinculados ao PPGAS/UFMT, perfazendo o total de produções que incluem resenhas, apresentações de dossiês, artigos livres ou outras contribuições. É interessante notar também a dispersão da origem de autores, distribuídos em todas as regiões do país, bem como das contribuições oriundas de pesquisadores do exterior, em um total de 15 artigos.

Aos docentes do PPGAS/UFMT tem cabido a tarefa de organizar dossiês, a partir de suas redes de pesquisas, eventos que coordenam e os temas que acabam por refletir nossa identidade enquanto programa. Desde a segunda edição, quando tivemos a publicação de um primeiro dossiê que versava sobre dança e cultura popular (vol. 1, n. 2), publicamos um total de 13 coletâneas de artigos organizadas por nossos professores em parceria com pesquisadores e pesquisadoras de outras regiões

\footnotetext{
${ }^{4}$ Total de autores do Centro-Oeste excluindo as contribuições dos autores do PPGAS da UFMT.
} 
brasileiras. Cada um desses dossiês aponta para linhas e redes de pesquisas que colocam o PPGAS/UFMT numa ampla teia de investigadores e pesquisas, apontando tanto para questões próprias ao nosso contexto centro-oestino, como para os temas gerais da antropologia contemporânea.

Os autores desses artigos são filiados a universidade de todos os estados brasileiros (tabela 3), o que nos faz crer que a Aceno contribuiu bastante nesses seis anos com a veiculação de conhecimentos vindos de lugares bastante distintos sobre a antropologia visual e do cinema (vol. 2, n. 3), a diversidade sexual e de gênero em contextos contemporâneos (vol. 3, n. 5), políticas quilombolas e de povos tradicionais (vol. 3, n. 6), cultura popular e performance (vol. 4, n. 7), conflitos na Amazônia (vol. 4, n. 8), parentalidades e conjugalidades (vol. 5, n. 9), políticas patrimoniais (vol. 6, n. 11), antropologia da saúde (vol. 6, n. 12), experiências etnográficas (vol. 7, n. 13), simbolismo sobre sangue (vol. 7, n. 14, no prelo) e formas de habitar (vol. 7, n. 15, no prelo).

A demanda por parte de autores/pesquisadores interessados em participar desses dossiês tem sido crescente nos últimos anos. Nossos últimos dossiês superaram, cada um deles, o número de 20 submissões, volume maior do que a tendência dos primeiros anos da revista. Esse aumento se deve tanto à visibilidade que a Aceno foi conquistando, ao primar por temáticas variadas e centrais na antropologia, quanto pelo fato desses dossiês refletirem a participação dos docentes do PPGAS/UFMT em grupos de trabalho presentes nos principais congressos da área, como a Reunião Brasileira de Antropologia ou mesmo na RAM e na REA/Abanne. Essa aposta em dossiês como carro-chefe de cada edição também faz da Aceno uma revista que prioriza a etnografia, os relatos de campos recentes que têm sido apresentados em congressos, revelando uma antropologia emergente do contemporâneo.

Outra questão importante são as bases de indexação em que a Aceno se encontra: Google Scholar, Sumários.org, Periódicos Capes, Diadorim, LatinREV e Latindex, o que não deixa de ser uma forma de reconhecimento do trabalho sério realizado pela Aceno. Com essa maior visibilidade do material publicado, a revista passou a ser considerada destino de pesquisa de autores renomados da antropologia brasileira, como José Guilherme Cantor Magnani, Eduardo Viveiros de Castro e Esther Jean Langdon, entre outros. E se esses artigos e dossiês apontam para conexões com as mais variadas antropologias que 
têm sido praticadas no país, a Aceno parece conquistar um lugar definitivo na seara editorial. Se esse impacto que a revista produz é inegável, os índices que avaliam o sucesso de empreitadas como a nossa podem ser tanto benéficos quanto cruéis ou mesmo injustos.

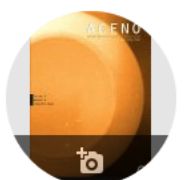

\section{Aceno Revista de Antropologia do Centro-Oeste}

Universidade Federal de Mato Grosso

E-mail confirmado em ufmt.br - Página inicial

Antropologia Teoria Antropológica Interdisciplinaridade

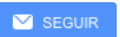

\begin{tabular}{lrr} 
Citado por & \multicolumn{2}{c}{ VISUALIZAR TODOS } \\
& Todos & Desde 2015 \\
\hline Citaçōes & 262 & 191 \\
Indice $h$ & 7 & 7 \\
Índice i10 & 5 & 5
\end{tabular}

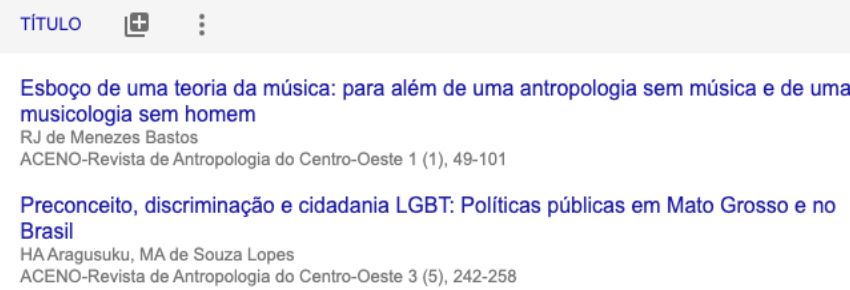

Esboço de uma teoria da música: para além de uma antropologia sem música e de uma musicologia sem homem

RJ de Menezes Bastos

ACENO-Revista de Antropologia do Centro-Oeste 1 (1), 49-10

Preconceito, discriminação e cidadania LGBT: Políticas públicas em Mato Grosso e no Brasil

HAAragusuku, MA de Souza Lopes

ACENO-Revista de Antropologia do Centro-Oeste 3 (5), 242-258

Diversidade Sexual e de Gênero, Ruralidade, Interioridade e Etnicidade no Brasil: Ausências, Silenciamentos e... Exortações.

F Gontijo, I Erick

ACENO-Revista de Antropologia do Centro-Oeste 2 (4), 24-40

Homossexualidade Indigena no Brasil: um roteiro histórico-bibliográfico ER Fernandes

ACENO-Revista de Antropologia do Centro-Oeste 3 (5), 14-38

A Diversidade Sexual e de Gênero em Contextos Rurais e Interioranos no Brasil: ausências, lacunas, silenciamentos e... exortações

F Gontijo, I Erick

ACENO: Revista de Antropologia do Centro-Oeste 2 (4), 24-40

A antropologia perspectiva e o método de equivocação controlada

$$
\text { EV de Castro }
$$

ACENO-Revista de Antropologia do Centro-Oeste 5 (10), 247-264

Discursos, performatividades e padrões visuais no cinema: reflexões sobre as representações de gênero, o mercado cinematográfico e o cinema de mulheres PAde Almeida, P Coelho

ACENO-Revista de Antropologia do Centro-Oeste 2 (3), 159-176

O sonho do nixi pae. A arte do MAHKU-Movimento dos Artistas Huni Kuin

AP Mattos
ACENO: Revista de Antropologia do Centro-Oeste 2 (3), 59-77

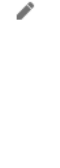

15

\section{Imagem 1 - Citações de artigos da Aceno no Fator de Impacto H5}

(Google Scholar)

Nesse sentido, há que se considerar também a relação que a Aceno possui com o Qualis Periódicos da Capes. Depois de uma primeira avaliação, no quadriênio 2012-2016, em que o estrato B3 já reconhecia o esforço da revista com apenas seis edições publicadas, o Qualis Referência, vazado em 2019 (cf. artigo de Olivia Cristina Perez, nesta edição de Novos Debates), deixou a Aceno ainda mais em evidência. Na nova avaliação, a revista apareceria no estrato A3, o que foi bastante comemorado por nós e fez com que o número de submissões crescesse, uma vez que se trata de um estrato superior. 


\section{Concluir: Olhando para o Futuro}

A experiência de produzir, nos rincões do Centro-Oeste, uma revista brasileira de Antropologia foi o nosso objetivo no presente texto. A ideia não foi lamentar as condições que possuímos, mas ressaltar que, apesar delas, tem sido possível realizar um trabalho de relativo sucesso. E esse sucesso não é apenas da Aceno; é revelador, talvez, da crescente importância das ciências humanas e sociais, em geral, e da antropologia, em particular, no escopo da ciência brasileira. As temáticas de nossas publicações e as redes para as quais elas apontam refletem tanto o crescimento do número de pesquisadores na área - o que torna oportuna e necessária a existência de mais periódicos - bem como as emergências de um Brasil contemporâneo ${ }^{5}$, cuja história se desdobra a nossos olhos e faz da Antropologia uma interlocutora privilegiada nos muitos conflitos de saberes e interesses

Políticas públicas, gênero, saúde, conflitos sociais e a situação das populações tradicionais constituem, não por acaso, temas caros a nossos autores e às redes de pesquisa que atravessam o PPGAS/UFMT. É possível afirmar, com isso, que a Aceno já é um canal privilegiado não apenas para a antropologia contemporânea, mas para os milhares e milhares de brasileiros cujas vozes se fazem ouvir no sem-número de páginas que dão vida aos relatos etnográficos. Vozes que indicam um Brasil que implementou progressivamente políticas sociais, e, ao mesmo tempo, um Brasil de indígenas, quilombolas e LGBTs que poucas vezes em sua história foram beneficiários de políticas governamentais, vivendo de eternas perdas ${ }^{6}$. Pensar a Aceno nesse emaranhado que conecta teorias, pesquisadores,

\footnotetext{
${ }^{5}$ Já em sua primeira edição, a Aceno dava destaque aos conflitos envolvendo comunidades indígenas na Amazônia (ver Oliveira 2014), bem como às sociabilidades de jovens em territórios marcados pela violência no Rio de Janeiro (ver Heilborn et al. 2014). E assim continuou em suas edições subsequentes nas quais tratou dos empecilhos aos direitos quilombolas (ver Silva 2015 e o dossiê organizado por Lourenço, et al. 2016) e a própria questão indígena que foi tema de dois dossiês (Beltrão $e t$ al. 2017; Cariaga e Crespe 2018). Em todos eles, ficou patente um país em que boa parte de sua população ainda luta por fazer valer os direitos garantidos na constituição.

${ }^{6}$ Assim como nos dossiês que trouxeram as perdas e lutas dos povos tradicionais, os campos de gênero e sexualidade e o da saúde se fizeram presentes em artigos e dossiês sensíveis às emergências de sujeitos contemporâneos em suas relações com as políticas públicas, tema que ganhou centralidade na Antropologia deste início de século XXI (ver Langdon 2015; Lopes et al. 2016; Vencato e Tarnovski 2018; Oliveira et al. 2019).
} 
sujeitos, coletivos, mazelas e belezas do Brasil contemporâneo, é considerar seu impacto real, para além de marcadores quantitativos.

\section{Referências Bibliográficas}

BELTRÃO, Jane; DELGADO, Paulo; O’DWYER, Eliane C. (orgs.). 2017. "Conflitos territoriais e socioambientais nas Amazônias” (dossiê temático). Aceno 4(8):11-14. Disponível em:

https://periodicoscientificos.ufmt.br/ojs/index.php/aceno /issue/view/429.

CAMPOS, Luiz Augusto. 2020. "Qualis, para que te quero?" Novos Debates 6(1-2):e6214. Disponível em: http://novosdebates.abant.org.br/2021/02/04/v6-n1-2$\underline{2020 /}$.

CARIAGA, Diógenes; CRESPE, Aline (orgs.). 2018. "Políticas Ameríndias" (dossiê temático). Aceno 5(10). Disponível em: https://periodicoscientificos.ufmt.br/ojs/index.php/aceno /issue/view/470.

HEILBORN, Maria Luíza; FAYA, Alfonsina; SOUZA, Josué F. 2014. "Juventude e Sociabilidade em um "território pacificado" no Rio de Janeiro: diversidade de experiências e seus marcadores sociais". Aceno 1(1):102-122. Disponível em:

https://periodicoscientificos.ufmt.br/ojs/index.php/aceno /article/view/1681.

LANGDON, Esther Jean. 2015. "Os diálogos da antropologia com a saúde: contribuições para as políticas públicas”. Aceno 2(4):55-77. Disponível em: https://periodicoscientificos.ufmt.br/ojs/index.php/aceno /article/view/3286,

LOPES, Moisés A. S. 2014. "Editorial". Aceno 1(1):6-9. Disponível em: https://periodicoscientificos.ufmt.br/ojs/index.php/aceno /article/view/1843.

LOPES, Moisés A. S.; GONTIJO, Fabiano de Souza; FERNANDES, Estêvão; TOTA, Martinho (orgs.). 2016. "Diversidade sexual e de gênero em áreas rurais, contextos interioranos e/ou situações etnicamente diferenciadas. Novos descentramentos em outras axialidades" (dossiê 
temático). Aceno 3(5). Disponível em: https://periodicoscientificos.ufmt.br/ojs/index.php/aceno /article/view/4142.

LOURENÇO, Sonia; SANTOS, Carlos A. P.; SILVA, Sandro J.; Mombelli, Raquel (Orgs.). 2016. "Cosmologias, territorialidades e políticas de quilombolas e de povos tradicionais" (dossiê temático). Aceno 3(6). Disponível em: https://periodicoscientificos.ufmt.br/ojs/index.php/aceno /issue/view/351.

OLIVEIRA, Esmael Alves de; SILVA, Marcos Aurélio da; VÍCTORA, Ceres Gomes (orgs.). 2019. "Nos contornos do corpo e da saúde: entre temas, problemas e perspectivas". Aceno 6(12). Disponível em: https://periodicoscientificos.ufmt.br/ojs/index.php/aceno /article/view/10246.

OLIVEIRA, João Pacheco. 2014. "Narrativas e imagens sobre povos indígenas e Amazônia: uma perspectiva processual da fronteira". Aceno 1(1):23-48, Disponível em: https://periodicoscientificos.ufmt.br/ojs/index.php/aceno /article/view/1709.

PEREZ, Olivia Cristina. 2020. "O novo Qualis Periódicos: Possíveis diretrizes, impactos e resistências". Novos Debates. Fórum 6(1-2):e2216. Disponível em: http://novosdebates.abant.org.br/2021/02/04/v6-n1-22020/.

SILVA, Sandro José. 2015. "O regime de Comodato como empecilho aos direitos dos quilombolas". Aceno 2(4):9-23. Disponível em: https://periodicoscientificos.ufmt.br/ojs/index.php/aceno /article/view/3380.

VENCATO, Anna Paula; TARNOVSKI, Flávio L. (orgs.). 2018. "Parentalidades, Conjugalidades e Gênero" (dossiê temático). Aceno 5(9). Disponível em: https://periodicoscientificos.ufmt.br/ojs/index.php/aceno /issue/view/469. 